\title{
A Ligand-Accelerated Chiral Lewis Acid Catalyst in Asymmetric Michael Addition of Thiols to $\alpha, \beta$-Unsaturated Carbonyls
}

\author{
Shū Kobayashi,* Chikako Ogawa, Mikako Kawamura, Masaharu Sugiura \\ Graduate School of Pharmaceutical Sciences, The University of Tokyo, CREST, Japan Science and Technology Corporation (JST), Hongo, \\ Bunkyo-ku, Tokyo 113-0033, Japan \\ Received 30 January 2001
}

Dedicated to Professor Ryoji Noyori in recognition of his remarkable contribution to Synthetic Organic Chemistry.

\begin{abstract}
A novel chiral hafnium catalyst, which was readily prepared from $\mathrm{Hf}(\mathrm{OTf})_{4}$ and chiral ligand $\mathbf{1}$, has been developed in asymmetric Michael reactions of thiols with 3-(2-alkenoyl)-2-oxazolidinones, affording the corresponding adducts in high yields and enantiomeric excesses. Although chiral Lewis acids are less reactive than their original Lewis acids in many cases, ligand-acceleration has been demonstrated in this asymmetric Michael addition reaction.
\end{abstract}

Key words: Lewis acid, Michael reaction, asymmetric catalysis

Ligand-acceleration is essential for catalytic asymmetric reactions. ${ }^{1}$ In some asymmetric oxidations and alkylations, chiral ligands coordinate to metals and accelerate the catalyzed reactions in a highly enantioselective manner. On the other hand, asymmetric reactions using chiral Lewis acids are now popular and recognized as one of the most efficient methods for the preparation of chiral molecules, especially via enantioselective carbon-carbon bond-forming processes. ${ }^{2}$ From the viewpoint of ligandacceleration, however, this is not the case with most chiral Lewis acid catalysis. Chiral Lewis acids are less reactive than their original Lewis acids in many cases, because basic chiral ligands coordinate to Lewis acids to form chiral Lewis acids, and in this coordination Lewis acids are neutralized to decrease Lewis acidity compared to the original Lewis acids. ${ }^{3}$ Development of a ligand-accelerated process in chiral Lewis acid catalysis is important to realize a truly efficient catalytic system. In this paper, we describe such examples of chiral hafnium-catalyzed asymmetric Michael addition of thiols to $\alpha, \beta$-unsaturated carbonyl compounds.

Catalytic Michael addition of thiols to $\alpha, \beta$-unsaturated carbonyls provides a useful route for the synthesis of chiral sulfur-containing molecules. ${ }^{4}$ Bearing in mind the ligand-accelerated chiral Lewis acids, we examined suitable combinations of Lewis acids and chiral ligands (1) in the asymmetric Michael reaction of 3-crotonoyl-2-oxazolidinone (2) with benzyl mercaptan. Several Lewis acids and ligands were examined and the results are shown in the Table. Among the Lewis acids screened, hafnium triflate $\left(\mathrm{Hf}(\mathrm{OTf})_{4}\right)^{5}$ gave better results, while ytterbium triflate $\left(\mathrm{Yb}(\mathrm{OTf})_{3}\right)$ or scandium triflate $\left(\mathrm{Sc}(\mathrm{OTf})_{3}\right)$ was promising. ${ }^{6}$

During this investigation, it was found that the catalytic activity of the chiral hafnium is higher than that of

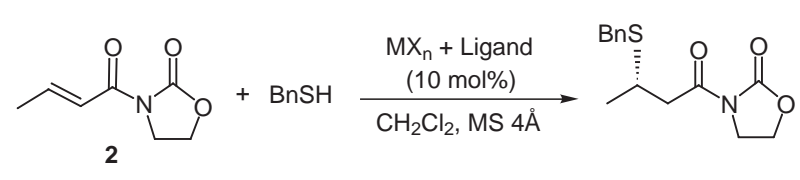

Table Effect of Ligands and Lewis Acids

\begin{tabular}{ccccc}
\hline \multicolumn{1}{c}{$\mathrm{MX}_{\mathrm{n}}$} & Ligand & Temp $\left({ }^{\circ} \mathrm{C}\right)$ & Yield $(\%)$ & ee $(\%)$ \\
\hline $\mathrm{Yb}(\mathrm{OTf})_{3}$ & 1a & -45 & 75 & 56 \\
$\mathrm{Yb}(\mathrm{OTf})_{3}$ & 1b & -45 & 82 & 61 \\
$\mathrm{Yb}(\mathrm{OTf})_{3}$ & $\mathbf{1 c}$ & -45 & 80 & 62 \\
$\mathrm{Sc}(\mathrm{OTf})_{3}$ & $\mathbf{1 c}$ & -45 & 73 & 57 \\
$\mathrm{Hf}(\mathrm{OTf})_{4}$ & 1c & 0 & 82 & 67 \\
$\mathrm{ScCl}$ & 1d & 0 & 15 & 45 \\
$\mathrm{Hf}(\mathrm{OTf})_{4}$ & $\mathbf{1 d}$ & 0 & 82 & 69 \\
$\mathrm{Hf}(\mathrm{OTf})_{4}$ & $\mathbf{1 e}$ & 0 & 76 & 60 \\
$\mathrm{Hf}(\mathrm{OTf})_{4}$ & $\mathbf{1 f}$ & 0 & 79 & 71 \\
$\mathrm{Hf}(\mathrm{OTf})_{4}$ & 1g & 0 & 85 & 69 \\
$\mathrm{Hf}(\mathrm{OTf})_{4}$ & 1h & 0 & 82 & 65 \\
$\mathrm{Hf}(\mathrm{OTf})_{4}$ & $\mathbf{1 i}$ & 0 & 72 & 21 \\
$\mathrm{HfCl}$ & $\mathbf{1 d}$ & 0 & 68 & 59 \\
$\mathrm{TiCl}(\mathrm{OTf})_{3}$ & 1d & 0 & 44 & 0 \\
$\mathrm{TiCl}_{4}$ & 1d & 0 & 92 & 6 \\
$\mathrm{MgBr}_{2}$ & 1d & 0 & 25 & 25 \\
\hline
\end{tabular}

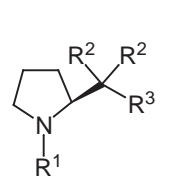

1a: $R^{1}=H, R^{2}=P h, R^{3}=O H$

1b: $\mathrm{R}^{1}=\mathrm{COPh}, \mathrm{R}^{2}=\mathrm{Ph}, \mathrm{R}^{3}=\mathrm{OH}$

1c: $R^{1}=$ COPh, $R^{2}=P h, R^{3}=O M e$

1d: $R^{1}=C O^{t} B u, R^{2}=P h, R^{3}=O M e$

1e: $R^{1}=$ COMe, $R^{2}=P h, R^{3}=O M e$

1f: $R^{1}=C^{t} B u, R^{2}=\alpha-N a p, R^{3}=O M e$

1g: $R^{1}=C O^{t} B u, R^{2}=\beta-N a p, R^{3}=O M e$

1h: $\mathrm{R}^{1}=\mathrm{CO} \mathrm{Bu}^{t} \mathrm{R} \mathrm{R}^{2}=c-\mathrm{C}_{6} \mathrm{H}_{11}, \mathrm{R}^{3}=\mathrm{OMe}$

1i: $R^{1}=C^{t} B u, R^{2}=\mathrm{Pr}, R^{3}=O M e$

$\mathrm{Hf}(\mathrm{OTf})_{4}$. While the desired Michael adduct was obtained in $58 \%$ yield in the addition of benzyl mercaptan to 2 in the presence of $10 \mathrm{~mol} \%$ of $\mathrm{Hf}(\mathrm{OTf})_{4}$ and MS $4 \AA$ in dichloromethane $\left(\mathrm{CH}_{2} \mathrm{Cl}_{2}\right)$ at $0{ }^{\circ} \mathrm{C}, 82 \%$ yield of the adduct was obtained using the chiral hafnium under the same reaction conditions. The difference between the two catalyst systems is the presence and absence of the chiral ligand. This is indeed an example of ligand-accelerated Lewis acid catalysis. We then carefully followed the reaction course in the presence and absence of the chiral ligand in the model Michael addition (Figure 1). It was revealed that the initial rate constant of the chiral hafniumcatalyzed reaction was 1.5 times larger than that of the 
achiral reaction. Although the value is not very satisfactory, the origin of the ligand acceleration is interesting from the viewpoint of very rare ligand-accelerated Lewis acid catalysis as well as development of more efficient catalytic systems. We performed kinetic experiments in the reaction of $\mathbf{2}$ with benzyl mercaptan. Rate constants $\left(k_{\mathrm{obs}}\right)$ were determined over a range of catalyst concentrations (5-15 mol\%), and a linear correlation between $k_{\text {obs }}$ vs $\left[\mathrm{Hf}(\mathrm{OTf})_{4}\right]^{2}$ was obtained, which reflected a second-order dependence on the catalyst (Figure 2). These kinetic data provide strong support for a mechanism involving catalyst activation of both the nucleophile and the electrophile that would explain the ligand-accelerated Lewis acid catalysis, although the detailed activation form is not clear at this stage. While $\mathrm{Hf}(\mathrm{OTf})_{4}$ is a white solid and does not dissolve in $\mathrm{CH}_{2} \mathrm{Cl}_{2}$, a clear solution was obtained after mixing with the ligand in $\mathrm{CH}_{2} \mathrm{Cl}_{2} \cdot{ }^{1} \mathrm{H}$ and ${ }^{13} \mathrm{C}$ NMR analyses showed formation of a novel chiral hafnium Lewis acid. ${ }^{8}$

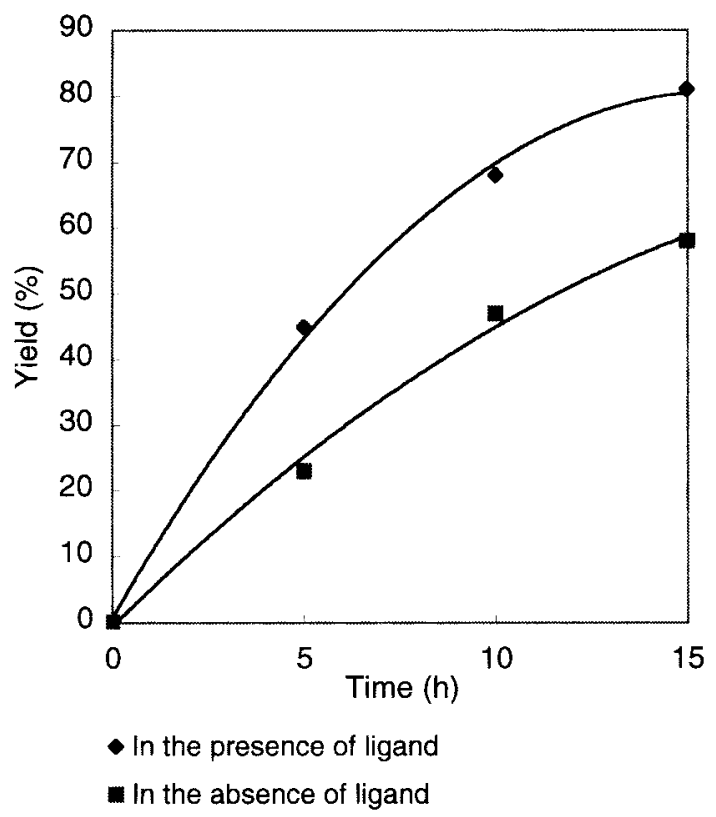

Figure 1 Plot of Isolated Yield vs Time in the Presence and Absence of the Ligand for the Michael Reaction of $\mathbf{2}$ with Benzyl Mercaptan

Several examples of the catalytic asymmetric Michael reactions are summarized in Table 2. In the presence of a catalytic amount of the chiral hafnium compound, aliphatic thiols reacted with 3-(2-alkenoyl)-2-oxazolidinones to afford the corresponding Michael adducts in high yields with high enantiomeric excesses. In some cases, ligands $\mathbf{1 j}$ and $\mathbf{1 k}$ gave better selectivity. Benzenethiols showed lower selectivity under these conditions.

A typical experimental procedure is described for the reaction of 2 with benzyl mercaptan: To a $\mathrm{CH}_{2} \mathrm{Cl}_{2}$ suspension $(1 \mathrm{~mL})$ of $\mathrm{Hf}(\mathrm{OTf})_{4}(0.05 \mathrm{mmol})$ and $\mathrm{MS} 4 \AA(125$ $\mathrm{mg}$ ) was added chiral ligand $\mathbf{1 j}(0.06 \mathrm{mmol})$ at $0{ }^{\circ} \mathrm{C}$. The mixture was stirred for $30 \mathrm{~min}$ at the same temperature.

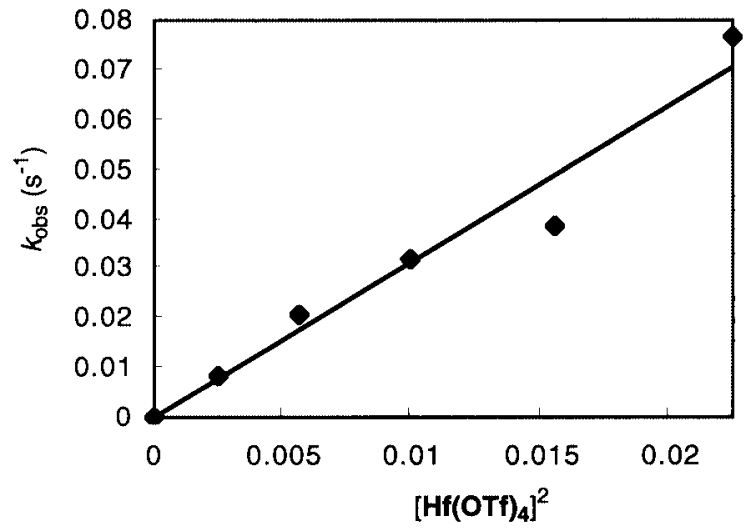

Figure 2 Plot $k_{\mathrm{obs}}$ vs $\left[\mathbf{H f}(\mathbf{O T f})_{4}\right]^{2}$ for the Michael Reaction of 2 with Benzyl Mercaptan

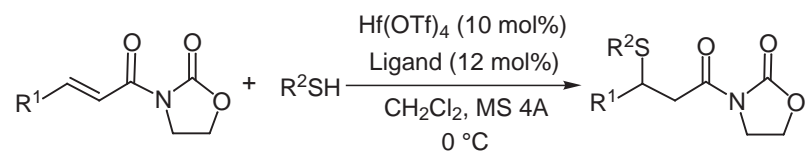

Table 2 Chiral Hafnium Complex-Catalyzed Asymmetric Michael Additions of Thiols

\begin{tabular}{cccccc}
\hline $\mathrm{R}^{1}$ & $\mathrm{R}^{2} \mathrm{SH}$ & Ligand & Time (h) & Yieid (\%) & ee (\%) \\
\hline $\mathrm{CH}_{3}$ & $\mathrm{C}_{2} \mathrm{H}_{5} \mathrm{SH}$ & $\mathbf{1 d}$ & 15 & 90 & 67 \\
$\mathrm{CH}_{3}$ & $-\mathrm{SH}^{\mathrm{a}, \mathrm{c})}$ & $\mathbf{1 d}$ & 15 & 60 & 76 \\
$\mathrm{CH}_{3}$ & $\mathrm{PhCH}_{2} \mathrm{SH}$ & $\mathbf{1 d}$ & 15 & 82 & 69 \\
$\mathrm{CH}_{3}$ & $\mathrm{PhCH}_{2} \mathrm{SH}$ & $\mathbf{1 j}$ & 22 & 53 & 92 \\
$\mathrm{CH}_{3}$ & $\mathrm{PhCH}_{2} \mathrm{SH}$ & $\mathbf{1 j}$ & 48 & 74 & 88 \\
$\mathrm{CH}_{3}$ & $\mathrm{C}_{4} \mathrm{H}_{9} \mathrm{SH}$ & $\mathbf{1 d}$ & 15 & 92 & 71 \\
$\mathrm{CH}_{3}$ & $\mathrm{C}_{4} \mathrm{H}_{9} \mathrm{SH}^{\mathrm{b})}$ & $\mathbf{1 j}$ & 15 & 80 & 90 \\
$\mathrm{CH}_{3}$ & $\mathrm{CH}_{2}=\mathrm{CHCH}_{2} \mathrm{SH}^{\mathrm{c}, \mathrm{d})}$ & $\mathbf{1 d}$ & 20 & 71 & 91 \\
$\mathrm{CH}_{3}$ & $\mathrm{CH}_{2}=\mathrm{CHCH}_{2} \mathrm{SH}^{\mathrm{c}, \mathrm{d})}$ & $\mathbf{1 k}$ & 20 & 83 & 94 \\
$\mathrm{C}_{4} \mathrm{H}_{9}$ & $+-\sqrt{-}-\mathrm{SH}^{\mathrm{d})}$ & $\mathbf{1 d}$ & 20 & 85 & 50 \\
$\mathrm{Ph}^{-}$ & $-\mathrm{SH}^{-}$ & $\mathbf{1 d}$ & 30 & 70 & 43 \\
\hline
\end{tabular}

a) Twenty mol $\%$ of hafnium triflate was used. ${ }^{\text {b) }}$ Fifteen mol $\%$ of hafnium triflate was used. ${ }^{c)}$ Thiol was added slowly over $8 \mathrm{~h} .{ }^{\mathrm{d})}$ The reaction was carried out at $5{ }^{\circ} \mathrm{C}$.
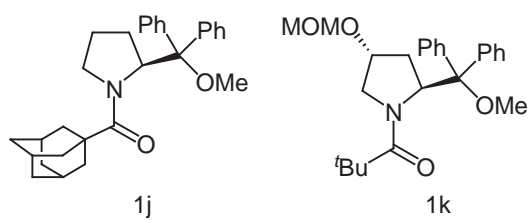

To this mixture, $2(0.5 \mathrm{mmol})$ in $\mathrm{CH}_{2} \mathrm{Cl}_{2}(1 \mathrm{~mL})$ and benzyl mercaptan $(0.55 \mathrm{mmol})$ in $\mathrm{CH}_{2} \mathrm{Cl}_{2}(1 \mathrm{~mL})$ were added successively at $0{ }^{\circ} \mathrm{C}$. After the mixture was stirred for 22 $\mathrm{h}$ at the same temperature, saturated aqueous $\mathrm{NaHCO}_{3}$ was added to quench the reaction. After the usual workup, the crude material was purified by preparative TLC to afford the desired Michael adduct. The enantiomeric ex- 
cess of the adduct was determined by HPLC analysis using a chiral column. The absolute configuration was determined to be $S$ compared with the authentic sample. ${ }^{4 \mathrm{f}}$ In summary, a novel chiral hafnium catalyst has been developed in asymmetric Michael reactions of thiols with 3-(2-alkenoyl)-2-oxazolidinones. The hafnium catalyst was readily prepared from $\mathrm{Hf}(\mathrm{OTf})_{4}$ and chiral ligand 1, and to the best of our knowledge, this is the first successful example of the use of chiral hafnium Lewis acids in asymmetric catalysis. ${ }^{9}$ Although chiral Lewis acids are less reactive than their original Lewis acids in many cases, ligand-acceleration has been demonstrated in this asymmetric Michael addition reaction. Further studies to clarify the structure of the chiral hafnium catalysts as well as the mechanism of the ligand-acceleration are now in progress.

\section{Acknowledgement}

This work was partially supported by a Grant-in-Aid for Scientific Research from the Ministry of Education, Science, Sports, and Culture, Japan.

\section{References and Notes}

(1) (a) Berrisford, D. J.; Bolm, C.; Sharpless, K. B. Angew. Chem., Int. Ed. Engl. 1995, 34, 1059.

(2) (a) Lewis Acids in Organic Synthesis, ed by Yamamoto, $\mathrm{H}$. Wiley-VCH: Weinheim, 2000. (b) Kobayashi, S.; Ishitani, H. Chem. Rev. 1999, 99, 1069.

(3) When chiral Lewis acids are prepared by ligand exchanges, ligand-acceleration is naturally observed. In this case, chiral ligands are introduced to original Lewis acids via covalent bonds. See for example, (a) Furuta, K.; Miwa, Y.; Iwanaga, K.; Yamamoto, H. J. Am. Chem. Soc. 1988, 110, 6254. (b) Nitta, H.; Yu, D.; Kudo, M.; Mori, A.; Inoue, S. J. Am. Chem. Soc. 1992, 114, 7969. See also (c) Mikami, K.; Terada,
M.; Korenaga, T.; Matsumoto, Y.; Ueki, M.; Angelaud, R. Angew. Chem., Int. Ed. 2000, 112, 3532, and Ref. 1.

(4) (a) Hiemstra, H.; Wynberg, J. Am. Chem. Soc. 1981, 103, 417. (b) Suzuki, K.; Ikegawa, A.; Mukaiyama, T. Bull. Chem. Soc. Jpn. 1982, 55, 3277. (c) Yamashita, H.; Mukaiyama, T. Chem. Lett. 1985, 363. (d) Nishimura, K.; Ono, M.; Nagaoka, Y.; Tomioka, K. J. Am. Chem. Soc. 1997, 119, 12974. (e) Emori, E.; Arai, T.; Sasai, H.; Shibasaki, M. J. Am. Chem. Soc. 1998, 120, 4043. (f) Kanemasa, S.; Oderaotoshi, Y.; Wada, E. J. Am. Chem. Soc. 1999, 121, 8675. (g) Saito, M.; Nakajima, M,; Hashimoto, S. Chem. Commun. 2000, 1851. (h) Kondo, T.; Mitsudo, T. Chem. Rev. 2000, 100, 3205. (i) Sibi, M. P.; Manyem, S. Tetrahedron 2000, 56, 8033.

(5) (a) Hachiya, I.; Moriwaki, M.; Kobayashi, S. Tetrahedron Lett. 1995, 36, 409. (b) Hachiya, I.; Moriwaki, M.; Kobayashi, S. Bull. Chem. Soc. Jpn. 1995, 68, 2053.

(6) (a) Kobayashi, S. Chem. Soc. Rev. 1999, 15. (b) Kobayashi, S. Lewis Acid in Organic Synthesis; ed by Yamamoto, H. WileyVCH: Weinheim, 2000; Vol. 2, p. 883-910. (c) Kobayashi, S. Synlett 1994, 689.

(7) For example, (a) Hansen, K. B.; Leighton, J. L.; Jacobsen, E. N. J. Am. Chem. Soc. 1996, 118, 10924. (b) Denmark, S. E.; Fu, J. J. Am. Chem. Soc. 2000, 120, 12021.

(8) $\mathrm{Hf}(\mathrm{OTf})_{4}$ : Ligand $=1: 1$ mixture in $\mathrm{CD}_{2} \mathrm{Cl}_{2}$ at $0{ }^{\circ} \mathrm{C} ;{ }^{1} \mathrm{H} \mathrm{NMR}$ $\delta=1.29(\mathrm{~s}, 3.96 \mathrm{H}), 1.22-1.32(\mathrm{~m}, 0.56 \mathrm{H}), 1.56(\mathrm{~s}, 5.04 \mathrm{H})$, $1.66-1.98(\mathrm{~m}, 1.76 \mathrm{H}), 2.21(\mathrm{~m}, 0.56 \mathrm{H}), 2.39-2.64(\mathrm{~m}, 1.56 \mathrm{H})$, $3.11(\mathrm{~s}, 1.32 \mathrm{H}), 3.72(\mathrm{br} \mathrm{s}, 1.68 \mathrm{H}), 3.91-4.00(\mathrm{~m}, 1 \mathrm{H}), 4.13$ $(\mathrm{t}, 0.56 \mathrm{H}, J=10.9), 5.49(\mathrm{t}, 0.44 \mathrm{H}, J=8.3), 5.59(\mathrm{dd}, 0.56 \mathrm{H}$, $J=12.0,5.6), 7.05(\mathrm{dd}, 1.12 \mathrm{H}, J=8.0,1.7), 7.29-7.35(\mathrm{~m}$, $0.88 \mathrm{H}), 7.38-7.59(\mathrm{~m}, 8 \mathrm{H}) ;{ }^{13} \mathrm{C} \mathrm{NMR} \delta=23.4,26.5,26.9$, 27.5, 27.8, 28.5, 36.0, 39.4, 47.4, 52.6, 53.5, 73.2, 76.7, 91.1, $97.5,118.8,121.5,125.2,126.3,128.3,129.2,129.28,129.37$, 129.42, 129.6, 129.9, 130.0, 130.1, 130.4, 132.1, 133.9, 136.5, 139.0, 178.1, 182.4.

(9) Cf. Habaue, S.; Sakamoto, H.; Baraki, H.; Okamoto, Y. Macromol. Rapid Commun. 1997, 18, 707.

Article Identifier:

1437-2096,E;2001,0,SI,0983,0985,ftx,en;Y03401ST.pdf 